\title{
High energy neutron treatment for pelvic cancers: study stopped because of increased mortality
}

\author{
R D Errington, D Ashby, S M Gore, K R Abrams, S Myint, D E Bonnett, S W Blake, T E Saxton
}

Medical Research Council Cyclotron Unit, Mersey Regional Centre for Radiotherapy and Oncology, Clatterbridge Hospital, Wirral L63 4JY R D Errington, FRCR, consultant in radiotherapy and oncolog $y$

S Myint, FRCR, consultant in radiotherapy and oncology D E Bonnett, PHD, Medical Research Council senior physicist

S W Blake, MSc, Medical Research Council physicist T E Saxton, BSC, cyclotron manager

Departments of Statistics and Computational Mathematics and Public Health, University of Liverpool, Liverpool L69 3BX

D Ashby, PHD, lecturer in medical statistics

K R Abrams, MSc, research student in medical statistics

Medical Research Council Biostatistics Unit, Cambridge, CB2 2BW S M Gore, PHD, senior statistician

Correspondence to: $\mathrm{Dr}$ Errington.

BMF 1991:302:1045-51
Abstract

Objective-To compare high energy fast neutron treatment with conventional megavoltage $x$ ray treatment in the management of locally advanced pelvic carcinomas (of the cervix, bladder, prostate, and rectum).

Design-Randomised study from February 1986; randomisation to neutron treatment or photon treatment was unstratified and in the ratio of 3 to 1 until January 1988, when randomisation was in the ratio 1 to 1 and stratified by site of tumour.

Setting-Mersey regional radiotherapy centre at Clatterbridge Hospital, Wirral.

Patients - 151 patients with locally advanced, nonmetastatic pelvic cancer ( 27 cervical, 69 of the bladder, seven prostatic, and $\mathbf{4 8}$ of the rectum).

Intervention-Randomisation to neutron treatment was stopped in February 1990.

Main outcome measures-Patient survival and causes of death in relation to the development of metastatic disease and treatment related morbidity.

Results -In the first phase of the trial 42 patients were randomised to neutron treatment and 14 to photon treatment, and in the second phase 48 to neutron treatment and 47 to photon treatment. The relative risk of mortality for photons compared with neutrons was 0.66 (95\% confidence interval 0.40 to 1.10) after adjustment for site of tumour and other important prognostic factors. Short term and long term complications were similar in both groups.

Conclusions - The trial was stopped because of the increased mortality in patients with cancer of the cervix, bladder, or rectum treated with neutrons.

\section{Introduction}

Compared with conventional megavoltage radiotherapy (with photons) high linear energy transfer radiation such as neutron beams has potential biological advantages that may lead to improved overall results when used to treat locally advanced tumours. ${ }^{\prime}$ These advantages were not shown, however, in randomised studies on the treatment of rectal cancer and cancer of the bladder with low energy neutron beams $\mathrm{s}^{2-6}$ and carcinoma of the cervix with mixed photon and neutron treatment schedules. Of the studies of mixed photon and neutron treatment only the one in patients with cancer of the prostate showed an advantage when neutrons were used as part of the radiation treatment,${ }^{89}$ but the validity of this observation has been questioned. ${ }^{10}$

Mixed photon and neutron treatment schedules were evolved to overcome the logistic problems posed by limited access to non-hospital based cyclotrons and were not based on any radiobiological rationale." Low energy neutrons are associated with excess morbidity when used alone to treat pelvic tumours, which may obscure any benefit to be derived from neutrons if they could be used to irradiate pelvic tumours with dose distributions similar to those obtained with megavoltage $x$ rays. ${ }^{1213}$

More recently, hospital based cyclotrons capable of producing high energy neutrons have been developed, and there is registry based evidence that these are associated with greatly reduced morbidity when used to treat patients with pelvic tumours. ${ }^{14}$ In view of this, further phase three randomised studies of treatment with high energy neutrons versus treatment with photons were initiated in patients with locally advanced pelvic tumours (of the cervix, bladder, prostate, and rectum) to define the role of neutron treatment at these sites and determine whether or not the potential biological advantages are real in terms of clinical outcomes.

The research programme at Clatterbridge Hospital had the following positive features: high energy neutron treatment was compared with modern megavoltage photon treatment; patient follow up on site and by research clinicians; randomisation from the outset, with a ratio of patients allocated to neutron treatment compared those allocated to photon treatment of 3 to 1 from 6 February 1986 until 11 January 1988, when the ratio was changed to 1 to 1 randomisation by permuted blocks of variable length and stratified by site of tumour; dual planning of eligible patients to avoid "non-evaluable" bias-patients were randomised only if the plans for both neutron and photon treatment were acceptable; a careful informed consent procedure.

Poor patient accrual was one argument for combining patients with cancer at different sites (cervix, bladder, rectum, and prostate) within a single randomised trial; site specific trials would have been entirely lacking in statistical power. A second reason was that although the specific tissues affected by morbidity due to radiation might differ among patients with cancer at different sites, the pooled data would give a clearer indication of whether morbidity was becoming the serious problem it had been shown to be when low energy neutrons were used. Collaboration with the American College of Radiology Radiation Therapy Oncology Group was not possible as in March 1988 poor patient recruitment led to their trials in patients with cervical and rectal cancer being abandoned. The group's trial of high energy neutrons versus photons in patients with cancer of the prostate, was closed in October 1990 with 178 patients entered.

In preparation for a mid-term review of the Clatterbridge cyclotron's research programme in December 1989 by a Medical Research Council subcommittee an ad hoc analysis of mortality and morbidity results was prepared. Randomisation in the council's trial of patients with pelvic tumours to high energy neutron treatment or photon treatment was suspended on 12 February 1990 . The decision was ratified by the cancer therapy committee of the council on 8 March 1990. In 
this paper we describe the sequence of events leading to that decision and the results on which it was based.

\section{Methods}

ELIGIBILITY

To be eligible for randomisation patients had to have histologically confirmed adenocarcinoma of the rectum or prostate, squamous cell carcinoma of the cervix, or transitional cell carcinoma of the bladder not previously treated by radiotherapy or chemotherapy. Patients who were 80 years old or over had a Karnofsky performance score of 40 or less, or were otherwise unfit for radical pelvic radiotherapy were not eligible; nor were those with a history of malignancy at another site or evidence of distant metastases. Patients entering the study all had locally advanced disease as determined by appropriate clinical (including examination under anaesthesia, cystoscopy, and sigmoidoscopy) and radiological investigations (including computed tomography). By TNM staging randomised patients therefore had $T_{3 a}, T_{3 b}$, or $T_{4}$ and $N_{0}, N_{1}$ or $N_{2}, N_{x}$ stage cancer in all sites studied.

\section{RADIATION TECHNIQUES AND DOSAGE}

Treatment in all patients was planned with a treatment simulator that incorporated information from diagnostic and planning computed tomograms. In all patients an initial large volume of the pelvis was treated to cover the primary tumour and pelvic lymph nodes. This was followed by a second phase, entailing treatment of a small volume of the pelvis, replanned on the basis of computed tomograms, to treat the primary tumour site with a $2 \mathrm{~cm}$ margin around the area of known macroscopic disease. In patients with cervical cancer intracavity treatment was given whenever possible after the first phase of pelvic radiotherapy and was followed, where appropriate, with a boost treatment to a small volume of the parametrium. Table I gives the dose schedules for each site.

For both neutron and photon treatment comparable dose distributions were achieved as confirmed by dual planning in the early phase of the study (see below). Three and four field techniques were used and plans accepted only when the variation of dose within the target volume did not deviate by more than $7.5 \%$ of the target absorbed dose (as specified in section 33 of International Commission on Radiation Units and Measurements report No 29). Isocentric treatment techniques were used with $8 \mathrm{MV} x$ rays (source to axis distance $100 \mathrm{~cm}$ ) from a linear accelerator or with a neutron beam generated by bombarding a beryllium target with $62 \mathrm{MeV}$ protons. ${ }^{15}$

\section{RANDOMISATION AND DUAL PLANNING}

During the initial phase (phase 1: from 6 February 1986 to 10 January 1988) 56 patients were randomised in the ratio of 3 to $1-42$ to neutron treatment and 14 to photon treatment - but without stratification by site of tumour. Block length (eight) was not disclosed to clinicians, and randomisation was performed at the hospital by using sealed envelopes prepared by one of us (SMG).

Dual planning (for neutron and photon treatment) for eligible patients was practised for the first 50 patients; all were in fact randomised because they had adequate radiotherapy plans for both modalities. Dual planning was then suspended. Analysis by intention to treat was adhered to strictly with no patient excluded from the analysis retrospectively on grounds of inadequacy of radiotherapy plan, thus avoiding nonevaluable bias.

From 11 January 1988, 1 to 1 randomisation (again by using sealed envelopes) by permuted blocks of length four or six (determined by simple randomisation) and stratified by site of tumour was adopted for patients with tumours of the cervix, bladder, rectum, or prostate.

\section{PATIENT FOLLOW UP}

During treatment all patients were seen weekly to record reactions to treatment. During the first year after treatment patients were seen monthly and computed tomography, and cystoscopy in those with bladder tumours, repeated every three months. For subsequent years patients were seen at intervals of two to three months. At each follow up visit tumour response was assessed; any morbidity due to radiation was scored by the European Organisation for Research on Treatment of Cancer/Radiation Therapy Oncology Group scoring criteria.

\section{OUTCOMES}

For the interim analysis the primary outcome was mortality from all causes. The secondary end point was severe toxicity caused by treatment as defined by the recurrence of a reaction scoring grade 3 or higher by the European Organisation for Research on Treatment of Cancer/Radiation Therapy Oncology Group scoring criteria.

\section{TRIAL SIZE}

During the first phase of unstratified randomisation accrual was 29 patients per annum. Referrals for cancers of the bladder and cervix doubled in the second phase of randomisation, when accrual increased to 46 patients per annum. Even so, a minimum target (to give a $50 \%$ power to detect a relative risk of $1 \cdot 30$; see below) of 300 randomised patients was not likely to be reached until 1993; the Medical Research Council midterm review of the programme was scheduled for December 1989. In the absence of a formal plan for interim analysis ad hoc analysis (of 134 patients randomised up to 12 September 1989) was undertaken before the council's visit to the hospital and intended mainly as a check on data quality.

Trial size was assessed in 1988 soon after the start of 1 to 1 randomisation stratified by site of tumour. Five randomised trials of treatment with low energy neutrons for carcinoma of the bladder or rectum had been published by the end of $1987 . .^{245}$ In March 1988 a non-random sample of 10 clinicians and physicists

TABLE I-Dose schedules with neutrons and photons in patients treated for pelvic cancer

\begin{tabular}{|c|c|c|c|c|}
\hline Type of radiation & $\begin{array}{l}\text { Radiation to large pelvic } \\
\text { volume (phase } 1 \text { ) }\end{array}$ & Radiation to & 11 pelvic volume (phase 2 ) & Total dose to tumour \\
\hline \multicolumn{5}{|c|}{$\begin{array}{l}\text { Patients with cancer of the bladder, } \\
\text { rectum, or prostate: }\end{array}$} \\
\hline Neutrons & $\begin{array}{l}14 \cdot 4 \mathrm{~Gy} \text { ( } 9 \text { fractions over } \\
21 \text { days: } 3 \text { fractions/week) }\end{array}$ & \multirow{2}{*}{\multicolumn{2}{|c|}{$\begin{array}{c}4 \cdot 8 \mathrm{~Gy} \text { ( } 3 \text { fractions over } \\
7 \text { days) } \\
20 \mathrm{~Gy} \text { (10 fractions over } \\
14 \text { days) }\end{array}$}} & $\begin{array}{c}19 \cdot 2 \mathrm{~Gy} \text { (12 fractions over } \\
28 \text { days) }\end{array}$ \\
\hline Photons & $\begin{array}{l}44 \mathrm{~Gy} \text { ( } 22 \text { fractions over } \\
30 \text { days: } 5 \text { fractions/week) }\end{array}$ & & & $\begin{array}{c}64 \mathrm{~Gy} \text { (32 fractions over } \\
44 \text { days) }\end{array}$ \\
\hline \multicolumn{5}{|c|}{ Patients with cancer of the cervix: } \\
\hline Neutrons & $14.4 \mathrm{~Gy}(9$ fractions over & \multirow{2}{*}{$\begin{array}{l}\text { Intracavity caesium } \\
\text { (by a selectron) } 16 \mathrm{~Gy} \\
\text { (point } \mathrm{A} \text { ) if possible or }\end{array}$} & $4 \cdot 8$ Gy ( 3 fractions over & \\
\hline Photons & $\begin{array}{c}21 \text { days }) \\
50 \text { Gy (25 fractions over } \\
35 \text { days })\end{array}$ & & $\begin{array}{c}7 \text { days }) \\
16 \text { Gy }(8 \text { fractions over } \\
10 \text { days })\end{array}$ & \\
\hline
\end{tabular}




\begin{tabular}{|c|c|c|c|c|c|c|}
\hline \multirow[b]{2}{*}{ Site of tumour } & \multicolumn{2}{|c|}{ Phase 1} & \multicolumn{2}{|c|}{ Phase 2} & \multicolumn{2}{|c|}{$\begin{array}{c}\text { Total } \\
\text { (death rate at one year) }\end{array}$} \\
\hline & Neutrons & Photons & Neutrons & Photons & Neutrons & Photons \\
\hline Cervix & 3 & 6 & 9 & 9 & $12(32 \%)$ & $15(22 \%)$ \\
\hline Rectum & 19 & 4 & 12 & 13 & $31(52 \%)$ & $17(44 \%)$ \\
\hline Bladder & 17 & 4 & 24 & 24 & $41(71 \%)$ & $28(44 \%)$ \\
\hline Prostate & 3 & 0 & 3 & 1 & $6(17 \%)$ & $1(0 \%)$ \\
\hline Total (death rate at one year) & $42(60 \%)$ & $14(32 \%)$ & $48(48 \%)$ & $47(41 \%)$ & $90(55 \%)$ & $61(38 \%)$ \\
\hline
\end{tabular}

with an interest or involvement in neutron treatment were asked to quantify their current belief about the failure rate of treatment with high energy neutrons in patients with pelvic cancer. The consensus belief was a modest advantage with neutron treatment (median relative risk was $1 \cdot 14$ for failure of photon treatment compared with high energy neutron treatment). Respondents were also asked what relative risk they would accept for high energy neutrons to be recommended routinely for treating cancer of the pelvis. The consensus was a relative risk of $50 / 38 \cdot 5=1 \cdot 30$ - that is, a $30 \%$ greater failure rate with photons than with high energy neutrons. Randomisation of 600 patients was indicated for $80 \%$ power to detect such a moderate difference in failure rates as $50 \% v 38.5 \%$ and randomisation of 300 patients for $50 \%$ power.

Respondents' belief about the failure rate of treatment with high energy neutrons also established that randomisation of patients was ethical: in March 1988 respondents put $26 \%$ of their belief that neutron treatment had a failure rate of $38.5 \%$ or less, but $28 \%$ of their belief that there were as many or more failures with high energy neutrons as with photons (a reference failure rate of $50 \%$ ). Disparity between repondents' belief in treatment with high energy neutrons and the posterior distribution derived from subsequent statistical overview (see appendix) of the five randomised trials of low energy neutrons in treating cancer of the bladder and rectum ${ }^{2-6}$ was considerable.

\section{DATA MONITORING COMMITTEE}

Acting on the interim analysis reports (analysis date 12 September 1989) prepared for the Medical Research Council subcommittee's site visit on 4 December 1989, the neutron subgroup met in January 1990 to suggest establishing an independent data monitoring committee to advise on stopping randomisation in the pelvic cancer trial. The data monitoring committee was presented with formal analysis of mortality and morbidity for all patients randomised up to 26 January 1990; interim analysis reports up to 12 September 1989; statistical overviews of published randomised trials of treatment with low energy neutrons versus photons for pelvic cancer and for cancers of the head and neck; and a summary of beliefs (in March 1988) about the failure rate of high energy neutron treatment for pelvic tumours.

Randomisation was suspended in February 1990 by one of us (RDE); this decision was ratified by the data monitoring committee and approved by the cancer therapy committee on 8 March 1990.

\section{STATISTICAL ANALYSIS}

Comparison of mortality by using life tables was used throughout, which makes proper allowance for differential follow up times induced by initial 3 to 1 randomisation. Randomisation was not stratified in the initial phase and was stratified only by site of tumour in the second phase, when the randomisation ratio was 1 to 1 , and so retrospective covariate adjustment was performed by Cox's proportional hazards model. ${ }^{16} 17$ Covariate adjustment allowed us to check that im- balances (especially in the first phase, when randomisation was not stratified) between patients randomised to treatment with neutrons and those randomised to treatment with photons did not cause bias in the estimation of the relative risks of death for the two treatments. Covariates were firstly design variables (site of tumour and phase of randomisation) and secondly those variables specified in advance by one of us (RDE) as being important prognostic indicators ( $\mathrm{T}$ stage, $\mathrm{N}$ stage, and Karnofsky index). Although $\mathrm{T}_{4 \mathrm{a}}$ stage has a different definition for tumours of the bladder and rectum, our anlaysis makes the reasonable assumption of similarity of relative risk (for example, for $\mathrm{T}_{3 \mathrm{~b}} v \mathrm{~T}_{3 \mathrm{a}}$ ) across all sites of tumour. Observations on mortality were censored on 26 January 1990, when the vital status of every patient was ascertained. For analyses of morbidity due to radiation observations were censored at the last recorded follow up visit. All analyses were by intention to treat. Protocol violations occurred in 11 patients (six treated with neutrons and five treated with protons) of 151 patients - namely, two patients with cervical cancer (incorrect histology), six with rectal cancer (five failed to receive protocol treatment and one with incorrect results on histological examination), and three with cancer of the bladder (two failed to receive protocol treatment and one with incorrect staging).

\section{Results}

By 26 January 1990, 151 patients had been randomised. Table II shows how they were distributed by site of tumour, phase of randomisation, and treatment. Accrual was $70 \%$ higher in the second phase compared with the first, with recruitment doubled for patients with cancer of the cervix or bladder. Figure 1 shows the estimated survivor function by treatment for cancers at all sites combined. Table II gives the (actuarial) death rate at one year by treatment group and phase of randomisation, and also by site of tumour and treatment group. Only one patient with cancer of the prostate was randomised to treatment with photons. The relative risk of mortality for treatment with photons compared with treatment with neutrons was estimated by using Cox's proportional hazards model. Comparing the two treatment regimens without adjusting for any covariates yielded a relative risk of $0.59(\mathrm{p}<0.025)$ - that is, patients treated with photons had an estimated time specific risk of dying 0.59 times that of patients treated with neutrons $(95 \%$ confidence interval 0.36 to 0.95 ).

Allowance for site of tumour changes the relative risk to $\mathbf{0 \cdot 6 2}$, and allowance for phase of randomisation changes it to $0 \cdot 65$. However, once the other important prognostic factors ( $\mathrm{T}$ stage, $\mathrm{N}$ stage, and Karnofsky index) are included, the effect of phase of treatment is negligible $(p=0.88)$, indicating that differences in survival by phase in table II are due to small imbalances in the randomised groups (table III) rather than to real changes in survival. The relative risk adjusted for site of tumour and other important prognostic factors was $0 \cdot 66(0 \cdot 40$ to $1 \cdot 10)$. 
Table IV shows important prognostic characteristics by site of tumour and treatment. Using Cox's proportional hazards model a combined risk score predicting survival can be calculated for each patient. Table $\mathrm{V}$ shows the risk score summation for site of tumour, $T$ and $\mathrm{N}$ stage, and Karnofsky index. Table VI shows the distribution of this risk score for both treatment groups. On average the patients treated with neutrons had a worse prognosis than those treated with photons in the first phase, when randomisation was not stratified by site of tumour, and patients with cancers of the rectum and bladder were overrepresented in the neutron group. This explains why the adjusted relative risk is slightly nearer to unity than the unadjusted relative risk.

Table VII summarises cause of death according to treatment and subdivided into deaths within a year of treatment and later deaths. The distribution by cause of all deaths was similar for the two treatment groups $\left(\chi^{2}=4 \cdot 74, \mathrm{df}=3\right)$; a relative excess of patients with rectal cancer had metastases (with or without local progression) compared with patients with cancer of the bladder $\left(\chi^{2}=7 \cdot 93, \mathrm{df}=3\right)$.

Table VIII summarises the morbidity due to radiation by site of tumour for early and late severe reactions (Radiation Therapy Oncology Group/ European Organisation for Research on Treatment of Cancer score 3, 4, or 5). There was very little difference between the treatments for early reactions and none for late reactions: by Cox's proportional hazards model (unadjusted for covariates) the relative risk of early severe reactions for photon treatment compared with neutron treatment was $0 \cdot 77$ (95\% confidence interval

TABLE III - Mean (SD) risk score [number of patients] by treatmen and phase of randomisation

\begin{tabular}{l}
\hline Phase of treatment \\
\hline $1^{\star}$ \\
2 Neutrons
\end{tabular}

TABLE IV - Major prognostic factors by site of tumour and treatment (neutrons or photons) in patients with pelvic cancer. Figures are numbers (percentages) of patients

\begin{tabular}{|c|c|c|c|c|c|c|c|}
\hline & \multicolumn{2}{|c|}{ Cervix } & \multicolumn{2}{|c|}{ Bladder } & \multicolumn{2}{|c|}{ Rectum } & \multirow[b]{2}{*}{ Prostate } \\
\hline & Neutrons & Photons & Neutrons & Photons & Neutrons & Photons & \\
\hline \multicolumn{8}{|l|}{ T stage: } \\
\hline $3 a$ & $2(17)$ & & $9(22)$ & $8(29)$ & $4(13)$ & & 1 \\
\hline $3 b$ & $6(50)$ & $13(88)$ & $23(56)$ & $14(50)$ & $13)$ & & \\
\hline 4 & $4(33)$ & $2(12)$ & $9(22)$ & $6(21)$ & $26(84)$ & $17(100)$ & $6^{\star}$ \\
\hline \multicolumn{8}{|l|}{ N stage: } \\
\hline 0 & $11(92)$ & $10(67)$ & $34(83)$ & $26(93)$ & $27(87)$ & $16 \quad(94)$ & $6^{\star}$ \\
\hline 1 & $1(8)$ & $5(33)$ & $5(12)$ & $2(7)$ & $3(10)$ & 16 & \\
\hline 2 or missing & & & $2+(4)$ & & 1 (3) & & 1 \\
\hline \multicolumn{8}{|l|}{ Karnofsky index: } \\
\hline 50 & & & $1(2)$ & $1(4)$ & $2(6)$ & $1 \quad(6)$ & \\
\hline 60 & $1(8)$ & $2(14)$ & $9(22)$ & $3(11)$ & $6(19)$ & $16)$ & \\
\hline 70 & $4(33)$ & $1(6)$ & $5(12)$ & $2(7)$ & $7(23)$ & $12(71)$ & $1^{\star}$ \\
\hline 80 & $2(17)$ & $5(33)$ & $19(46)$ & $14(50)$ & $13(42)$ & 3 (17) & 4 \\
\hline 90 & $4(33)$ & $5(33)$ & $4(10)$ & $8(29)$ & $2(6)$ & 0 & 2 \\
\hline 100 & $1(8)$ & $2(14)$ & $3(7)$ & & & & \\
\hline
\end{tabular}

*Prognostic factors of the one patient with cancer of the prostate randomised to photon treatment.

tN stage was missing for one of these patients.

TABLE $\mathrm{V}-$ Risk score summation for site of tumour, stage, and Karnofsky index

\begin{tabular}{lcccccc}
\hline Site of tumour & Risk score & T stage & Risk score & N stage & Risk score & $\begin{array}{c}\text { Karnofsky index } \\
\text { Risk score }\end{array}$ \\
\hline Cervix & $-1 \cdot 12$ & 3a & 0 & 0 & 0 & \\
Bladder & 0 & $3 \mathrm{~b}$ & $0 \cdot 27$ & 1 & $0 \cdot 73$ & $-0.026 \times$ Karnofsky \\
Rectum & $0 \cdot 04$ & $4 \mathrm{a}$ & $0 \cdot 09$ & 2 & $0 \cdot 83$ & \\
Prostate & -0.81 & $4 \mathrm{~b}$ & $0 \cdot 01$ & & & \\
\hline
\end{tabular}

Example: risk score for patient with cancer of the bladder, stage $\mathrm{T}_{3 \mathrm{~B}}, \mathrm{~N}_{0}$ and Karnofsky index of $80=0+0 \cdot 27+0-0 \cdot 026=-1 \cdot 81$.

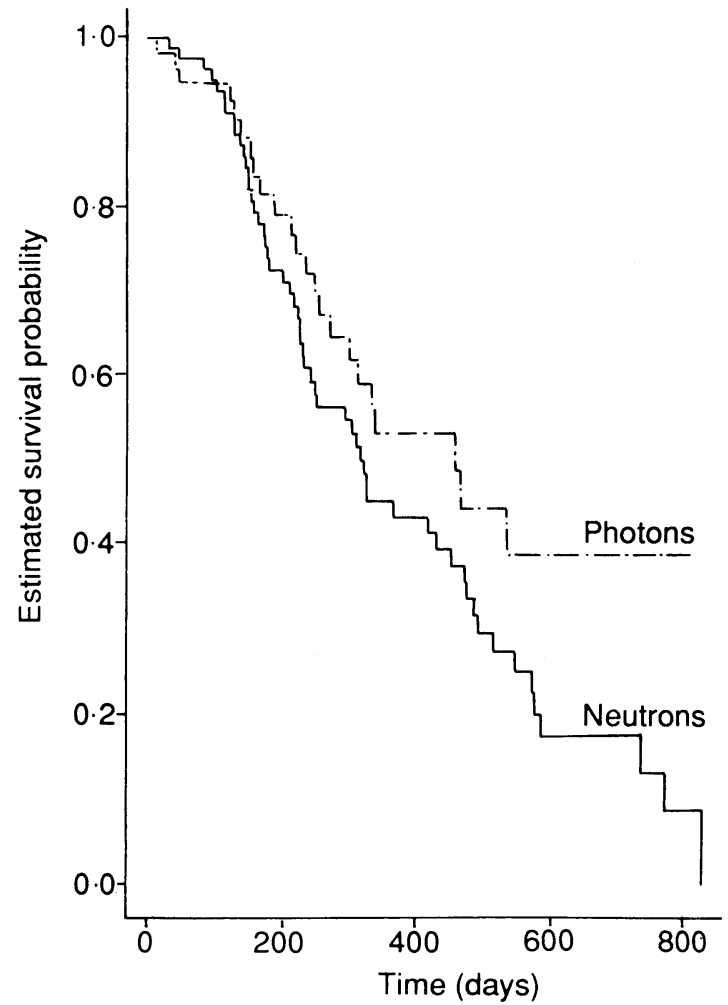

Estimated probability of survival in patients with pelvic cancer randomised to treatment with neutrons or photons (analysis of results until 26 fanuary 1991)

TABLE VI-Number (percentage) of patients in each category of risk score for treatment with photons $v$ treatment with neutrons

\begin{tabular}{|c|c|c|}
\hline Category of risk score & Neutrons & Photons \\
\hline$-3 \cdot 99--3 \cdot 50$ & $1 \quad(1)$ & $\begin{array}{ll}0 & (0)\end{array}$ \\
\hline$-3 \cdot 49--3 \cdot 00$ & $6 \quad(7)$ & $5 \quad(8)$ \\
\hline$-2 \cdot 99--2 \cdot 50$ & 10 (11) & $5 \quad(8)$ \\
\hline$-2 \cdot 49--2 \cdot 00$ & $29(32)$ & 20 \\
\hline$-1.99--1.50$ & 25 & 24 (39) \\
\hline$-1 \cdot 49--1.00$ & $16(18)$ & $6 \quad(10) \times p \%$ \\
\hline$-0.99--0.50$ & 2 (2) & 1 (2) \\
\hline$-0.49--0.00$ & 1 (1) & $\begin{array}{ll}0 & (0)\end{array}$ \\
\hline Total & $90(100 \%)$ & $61(100 \%)$ \\
\hline
\end{tabular}

0.29 to 2.04$)$ and of late severe reactions $0.85(0.39$ to $1 \cdot 89$ ).

Patients with cancer of the prostate showed no early or late severe reactions, and for the others only three sites were involved for early reactions: the upper gastrointestinal tract, the lower gastrointestinal tract, and the bladder. For severe late reactions the sites most frequently involved were lower gastrointestinal tract and bladder.

\section{Discussion}

When designing a clinical trial to compare two treatments the first priority is unbiased comparison, and the second is a powerful comparison. The trial of neutron treatment versus photon treatment achieved the first of these, but given the anticipated effects, combined with patient accrual, the second was always likely to be a problem.

Clinical opinion was elicited formally and indicated a median expectation of results for neutron treatment being favourable compared with photon treatment, but there was sufficient uncertainty to justify randomisation. Nevertheless, the conflict between clinical opinion and the results of the studies on treatment with low energy neutrons (see appendix) should have meant that formal stopping rules were incorporated to guard against the possibility of adverse mortality or morbidity. 


\begin{tabular}{|c|c|c|c|c|c|c|c|c|}
\hline \multirow[b]{2}{*}{ Cause of death } & \multicolumn{2}{|c|}{$\begin{array}{l}\text { Deaths within one year } \\
\text { after randomisation }\end{array}$} & \multicolumn{2}{|c|}{ Deaths after one year } & \multicolumn{2}{|c|}{ Total No of deaths } & \multirow{2}{*}{$\begin{array}{l}\text { Patients with } \\
\text { cancer of the } \\
\text { bladder }\end{array}$} & \multirow{2}{*}{$\begin{array}{l}\text { Patients with } \\
\text { cancer of the } \\
\text { rectum }\end{array}$} \\
\hline & Neutrons & Photons & Neutrons & Photons & Neutrons & Photons & & \\
\hline Metastases & 5 & & & 1 & 5 & 1 & 5 & 1 \\
\hline $\begin{array}{l}\text { Metastases and local tumour } \\
\text { progression }\end{array}$ & 21 & 5 & 7 & 2 & 28 & 7 & 12 & 20 \\
\hline $\begin{array}{l}\text { progression } \\
\text { Local progression }\end{array}$ & 13 & 12 & 4 & 1 & 17 & 13 & 16 & 8 \\
\hline Morbidity due to treatment & & & 3 & 1 & 3 & 1 & 2 & 1 \\
\hline New primary cancer & & & 2 & & 2 & & & \\
\hline Intercurrent disease & 2 & 2 & & & 2 & 2 & 3 & 1 \\
\hline Total & 41 & 19 & 16 & 5 & 57 & 24 & 38 & 31 \\
\hline
\end{tabular}

TABLE VIII - Early (within 90 days) and late morbidity due to radiation by Radiation Therapy Oncology Group/European Organisation for Research on Treatment of Cancer scoring by (neutrons or photons) and site of tumour. Figures are numbers of patients unless stated otherwise

\begin{tabular}{|c|c|c|c|c|c|c|c|c|c|}
\hline & \multicolumn{2}{|c|}{ Cervix } & \multicolumn{2}{|c|}{ Bladder } & \multicolumn{2}{|c|}{ Rectum } & \multirow[b]{2}{*}{ Prostate* } & \multicolumn{2}{|c|}{ All sites } \\
\hline & Neutrons & Photons & Neutrons & Photons & Neutrons & Photons & & Neutrons & Photons \\
\hline \multicolumn{10}{|l|}{ Early morbidity: } \\
\hline No randomised & 12 & 15 & 41 & 28 & 31 & 17 & 7 & 90 & 61 \\
\hline $\begin{array}{l}\text { No with } \geqslant 1 \text { severe early } \\
\text { reaction }\end{array}$ & 1 & 1 & 9 & 2 & 2 & 3 & 0 & 12 & 6 \\
\hline $\begin{array}{l}\text { Actuarial \% with } \geqslant 1 \text { severe } \\
\text { reaction within three } \\
\text { months after } \\
\text { randomisation }\end{array}$ & 11 & 8 & 27 & 9 & 7 & 23 & 0 & 16 & 12 \\
\hline \multicolumn{10}{|l|}{ Late morbidity: } \\
\hline No of survivors at 90 days & 9 & 14 & 35 & 23 & 30 & 14 & 7 & 80 & 52 \\
\hline $\begin{array}{l}\text { No with } \geqslant 1 \text { severe late } \\
\text { reaction }\end{array}$ & 2 & 3 & 8 & 4 & 6 & 3 & 0 & 16 & 10 \\
\hline $\begin{array}{l}\text { Actuarial } \% \text { with } \geqslant 1 \text { severe } \\
\text { reaction within one year } \\
\text { after randomisation }\end{array}$ & 21 & 15 & 40 & 24 & 16 & 27 & 0 & 24 & 21 \\
\hline
\end{tabular}

*Only one of seven patients was randomised to photon treatment.

Because the trial was randomised the main results were presented for the comparison between neutron treatment and photon treatment, unadjusted for any other factor. However, because the trial was randomised in two phases and only in the second phase was stratified by site of tumour the relative risk of photon treatment compared with neutron treatment was re-estimated taking these and other important covariates into account. This modified the relative risk but did not substantially alter the conclusions of the unadjusted analysis. Covariate adjustment for other important prognostic factors had a similar effect. The $95 \%$ confidence interval extends to 1.10 but clearly excludes a relative risk of $1 \cdot 30$, at which neutrons would be recommended for treatment, and is consistent with a relative risk of 0.65 from the statistical overview of randomised trials of low energy neutron treatment for tumours of the rectum and bladder.

Another consideration is whether the estimate of the relative risk should be adjusted for early stopping of the trial. This was not done formally in this study because the informal analysis was undertaken for a scheduled visit to the hospital and was not motivated by any knowledge of the results. Pocock and Hughes have shown that clinical trials that stop early are prone to exaggerate the difference between treatments. ${ }^{18}$ Continuing the trial just to obtain unbiased estimates of the treatment effect would, however, have been unethical given that the test treatment (neutrons) was proving inferior.

Because of the trial's design -we studied patients with cancer at four separate sites but with similar protocols and initial joint randomisation-it is debatable whether the data should be analysed as one trial or four. Had the trials continued to completion interest would undoubtedly have been focused on the relative risk or benefits of neutrons at each site. However, the power to look at each site separately is weak; indeed, it had been questioned whether there were enough data for a combined analysis. Because of the magnitude of effect, combined with internal consistency across patients with tumours at different sites and external consistency with results for treatment with low energy neutrons, the data monitoring committee concluded that there was sufficient evidence of adverse mortality in patients treated with neutrons to stop the trials, although there were insufficient data to quantify the excess risk with any accuracy.

Another issue is clinical significance versus statistical significance. In this trial the difference in mortality was large, but the primary difference between the results of the first informal analysis and those presented formally for the data monitoring committee was that the statistical significance of the relative risk for mortality changed from $p=0.07$ to $p=0.025$, which gave stronger evidence against the null hypothesis of no treatment difference. The important yardstick, however, is not equality of effect but the difference that would be required to change clinical practice. This was estimated in March 1988 to be a $30 \%$ greater failure rate for photon treatment by the respondents to the inquiry made by one of us (SMG). This difference was well outside the $95 \%$ confidence interval, even at the first informal analysis, and it could be argued that the trials should have been suspended on those grounds alone.

There was an intrinsic asymmetry between the two treatments, with one being an established treatment readily available to patients not in the trial and the other being an experimental treatment available at only one site in the United Kingdom. Had the difference been in the reverse direction, in favour of neutron treatment, the trial would be continuing in order to get a better estimate of the superiority of the new treatment. Ethically this would have been justified by considerations of limited resources-that is, that neutron treatment could not currently be offered to all patients. This is in contrast with drugs trials, where it is often feasible quickly to make a new treatment widely available. However, in this trial, with the new treatment showing an adverse effect, to have continued with the trial to gain a better estimate of the difference between neutron and photon treatments would have 
entailed continuing to randomise some patients to a treatment with an almost certainly worse prognosis than the treatment they would have received if they did not enter the trial. Randomisation was suspended by one of us (RDE) in February 1990 because it was thought to be unethical to continue to randomise patients. Monitoring of patients continues, and to that extent more information on neutron treatment versus photon treatment will become available, especially as regards morbidity in the survivors.

A lesson learnt from this trial is that all trials of this kind, with mortality as an outcome and potentially causing severe toxicity, should have a data monitoring committee in place from the start of the trial. Its role is to decide how and when to monitor results and to share responsibility for decisions to stop or continue trials. This avoids the difficult situation where individual clinicians are forced to make these decisions with little external support or guidance.

In the low energy neutron studies in patients with cancer of the bladder the increased mortality associated with neutrons was related to increased morbidity compared with that caused by photons rather than differences in local tumour control or metastatic relapse. $^{23}$ This contrasts with the present study, in which the morbidity data showed no significant difference between neutron treatment and photon treatment. This observation, however, needs to be interpreted with caution as follow up times were short and the poor survival of patients treated with neutrons depleted the number available for the full assessment of more serious late complications. Despite this reservation the assumption that high energy neutrons, with improved physical dosimetry, would be associated with less normal tissue morbidity may be correct. This does not, however, lead to any benefit from high energy neutron treatment in terms of survival or freedom from metastatic disease.

We emphasise that these conclusions are not applicable at this stage to patients with locally advanced prostatic adenocarcinoma in view of the small number of such patients recruited to this study, only one of whom was randomised to treatment with photons. There is evidence supporting the use of mixed beam therapy in patients with carcinoma of the prostate, ${ }^{8}$ and accrual to a phase three Radiation Therapy Oncology Group study of treatment with neutrons alone versus treatment with photons was closed in October 1990 with 178 patients entered, though it will be several years before the results of this trial are available. In conclusion, the results of this study do not support the continued use of the stated schedules (table I) of high energy neutrons in the treatment of locally advanced carcinomas of the cervix, bladder, or rectum.

We thank Sister Rose Dixon, cyclotron nurse; Mrs J Neale, cyclotron superintendent radiographer; Miss S Minnis, trials secretary; and Mrs E Batty for their contributions. We also thank Professor G R H Sealy, clinical director of the Mersey regional centre for radiotherapy and oncology for advice; the Medical Research Council data monitoring committee (chairman Mr R R Hall with Dr J A Lewis, chief statistician; the medical affairs department, Imperial Chemical Industries; and $\operatorname{Dr} T \mathrm{~J}$ Priestman, consultant in radiotherapy and oncology, Wolverhampton); the neutron therapy steering committee (chairman Professor C A F Joslin); and Dr F Spencer (Medical Research Council head office). The Clatterbridge cyclotron facility was established as a jointly funded initiative between the Medical Research Council, Imperial Cancer Research Fund, Cancer Research Campaign, Clatterbridge Cancer Research Trust, and the Cancer and Polio Research Fund in collaboration with Mersey Regional and Wirral Health Authorities and the University of Liverpool. Professor H M Warenius was Medical Research

\section{APPENDIX}

Statistical overview of randomised trials of low energy neutron treatment versus photon treatment for cancer of the bladder or rectum

(1) Batterman: 34 patients with advanced tumours of the bladder or rectum were randomised to treatment with photons, 31 to treatment with neutrons at $17 \mathrm{~Gy}$, and 26 to treatment with neutrons at $19 \mathrm{~Gy}$. Results were given as an artist's impression of Kaplan-Meier survival curves, from which we read one year survival rates as $39 \%$ for neutrons at $17 \mathrm{~Gy}, 44 \%$ for neutrons at 19 $\mathrm{Gy}$, and $47 \%$ for photons. Analysis was without exclusion of patients after randomisation.

(2) Pointon $e t a l^{5}: 53$ patients with stage $T_{2}$ or $T_{3}$ cancer of the bladder were randomised (by telephone) to treatment with photons, 28 to low dose neutrons, and 27 to high dose neutrons. Analysis was without exclusion of patients after randomisation; 16

Mantel-Haenszel ${ }^{19}$ overview of six trials of neutron $v$ photon treatment

\begin{tabular}{|c|c|c|c|c|c|c|c|}
\hline \multirow[b]{2}{*}{ Trial } & \multirow[b]{2}{*}{ Site of tumour } & \multicolumn{3}{|c|}{ Outcome at one year } & \multicolumn{3}{|c|}{$\begin{array}{l}\text { Survivors of neutron treatment } \\
\text { at one year }\end{array}$} \\
\hline & & & Alive & Dead & Observed & Expected & Variance \\
\hline Batterman' & Bladder, rectum & $\begin{array}{l}\text { Neutrons } \\
\text { Photons }\end{array}$ & $\begin{array}{l}23 \\
16\end{array}$ & $\begin{array}{l}34 \\
18\end{array}$ & 23 & $24 \cdot 429$ & $5 \cdot 273$ \\
\hline Pointon" & Bladder & $\begin{array}{l}\text { Neutrons } \\
\text { Photons }\end{array}$ & $\begin{array}{l}39 \\
42\end{array}$ & $\begin{array}{l}16 \\
11\end{array}$ & 39 & $41 \cdot 250$ & $5 \cdot 108$ \\
\hline Duncan $^{+}$ & Bladder & $\begin{array}{l}\text { Neutrons } \\
\text { Photons }\end{array}$ & $\begin{array}{l}27 \\
43\end{array}$ & $\begin{array}{l}26 \\
17\end{array}$ & 27 & $32 \cdot 832$ & 6.693 \\
\hline Duncan ${ }^{+}$ & (Inoperable) Rectum & $\begin{array}{l}\text { Neutrons } \\
\text { Photons }\end{array}$ & $\begin{array}{r}3 \\
10\end{array}$ & $\begin{array}{r}17 \\
6\end{array}$ & 3 & $7 \cdot 222$ & $2 \cdot 109$ \\
\hline Duncan ${ }^{4}$ & (Recurrent) Rectum & $\begin{array}{l}\text { Neutrons } \\
\text { Photons }\end{array}$ & $\begin{array}{r}5 \\
11\end{array}$ & $\begin{array}{r}10 \\
5\end{array}$ & 5 & $7 \cdot 742$ & 1.998 \\
\hline Duncan 1987 & Bladder (unpublished) & $\begin{array}{l}\text { Neutrons } \\
\text { Photons }\end{array}$ & $\begin{array}{l}2 \\
1\end{array}$ & $\begin{array}{l}4 \\
3\end{array}$ & 2 & 1.800 & 0.560 \\
\hline Total & & & & & 99 & $115 \cdot 275$ & $21 \cdot 741$ \\
\hline
\end{tabular}

$\chi^{2}=\frac{[(115 \cdot 275-99)-0.5]^{2}}{21 \cdot 741}=11 \cdot 45(z=3.38)$.

Odds ratio $=\frac{14 \cdot 490}{30 \cdot 765}=0 \cdot 47(95 \%$ confidence interval $0 \cdot 30$ to $0 \cdot 73)$.

Derived relative risk ${ }^{20}=0 \cdot 65(0 \cdot 50$ to $0 \cdot 84)$. patients did not, however, complete the treatment to which they were randomised. From life tables, shown as a step function for all patients randomised to neutron treatment we read one year survival rates as $70 \%$ for neutron treatment and $80 \%$ for photon treatment.

(3) Duncan et $a^{2}: 60$ patients with transitional cell carcinoma of the bladder stratified by $T$ stage and histological grade into four groups were randomised (by using sealed envelopes) to treatment with photons and 53 to treatment with neutrons. Treatment had to be started within 14 days of randomisation; no patient was excluded from analysis. From life tables we read one year survival rates as $50 \%$ for the neutron group and $72 \%$ for the photon group. $(4,5$, and 6) Duncan et al $: 10$ out of 77 patients were excluded after randomisation (patients were stratified, and sealed envelopes were used), of whom four had drawn photon treatment and six neutron treatment. Of the excluded patients, one out of four had survived photon treatment at one year after randomisation and two out of six had survived neutron treatment (G R Kerr, personal communication). Actuarial survival rates at one year were tabulated separately for patients analysed in the trial of patients with inoperable cancer and for patients analysed in the trial of patients with recurrent cancer. One year survival rates were $15 \%$ (neutron group), 62\% (photon group) and 33\% (neutron group), $69 \%$ (photon group) respectively.

Patients with inoperable cancer were stratified according to whether the inoperability was due to the extent of the tumour ( 15 were assigned to photon treatment, 16 to neutron treatment) or age or general condition (one in the photon group, four in the neutron group). In the trial of patients with recurrent cancer 16 of those randomised to photon treatment and 15 of those randomised to neutron treatment were analysed. Both trials closed in May 1984 because it was feared that similar radiation morbidity or mortality, or both, might be experienced by patients in these trials as had been seen in a concurrent trial of neutron treatment for bladder cancer (trial 6).

Trials 3, 4, and 5 were terminated because of concerns about radiation morbidity or mortality, or both, in patients randomised to low energy neutron treatment. A figure of 99 survivors of low enery neutron treatment at one year after randomisation is more than 3.3 standard errors fewer than expected (that is, 115.3) if death rates were identical with photon treatment and low energy neutron treatment. The pooled relative risk $(95 \%$ confidence interval) of death within one year after randomisation (photon $v$ low energy neutrons) was $0.65(0.50$ to 0.84$){ }^{20}$ 
Council honorary clinical coordinator for part of the study period. The Clatterbridge neutron therapy research programme is managed and funded by the Medical Research Council. K R Abrams is supported by a grant from the North West Cancer Research Fund. We also thank the following clinical colleagues for their support: Mr D A Berstock, Dr A J Slater, Dr J E S Brock, Dr M A Coe, Dr B Cottier, and Dr B Jones.

1 Wambersie A, Bewley DK, Lalanne CM. Prospects for the application of fast neutrons in cancer therapy. Bull Cancer (Paris) 1986;73:546-61

2 Duncan W, Arnott SJ, Jack WJL, et al. A report of a randomized trial of $\mathrm{d}(15)+\mathrm{Be}$ neutrons compared with megavoltage $\mathrm{x}$-ray therapy of bladder cancer. Int f Radiat Oncol Biol Phys 1985;11:2043-9.

3 Duncan W, Williams JR, Kerr GR, et al. An analysis of the radiation related morbidity observed in a randomized trial of neutron therapy for bladder cancer. Int F Radiat Oncol Biol Phys 1986:12:2085-92.

+ Duncan W, Arnott SJ, Jack WJL, Orr JA, Kerr GR, Williams JR. Results of two randomised clinical trials of neutron therapy in rectal adenocarcinoma. Radiother Oncol 1987;8:191-8.

5 Batterman JJ. Results of $d+T$ fast neutron irradiation on advanced tumors of bladder and rectum. Int 7 Radiat Oncol Biol Phys 1982;8:2159-64.

6 Pointon RS, Read G, Green D. A randomised comparison of photons and 15 $\mathrm{MeV}$ neutrons for the treatment of carcinoma of the bladder. Br f Radiol 1985;58:219-24.

7 Maor MH, Gillespie BW, Peters LJ, et al. Neutron therapy in cervical cancer: results of a phase III RTOG study. Int $\mathcal{f}$ Radiat Oncol Biol Phys 1988; 14:885-91.
8 Laramore GE, Krall JM, Thomas FJ, et al. Fast neutron radiotherapy for locally advanced prostate cancer: results of an RTOG randomized study. In f Radiat Oncol Biol Phys 1985;11:1621-7.

9 Laramore GE. The cyclotron saga. BMF 1990;301:344.

10 MacDougall RH, Arnott SJ. The cyclotron saga. BMF 1990;300:1721

11 Peters LJ, Maor H, Laramore GE, et al. Review of clinical results of fast neatron therapy in the USA. In: Maruyama Y, Beach JL, Feola JM, eds. Californium-252 brachytherapy and fast neutron beam therapy. Nuclear Californium-252 brachytherapy and fast neuro
Science Applications Section $B$ 1986;2:243-60.

12 Griffin TW, Wambersie A, Laramore GE, Castro J. High LET: heavy particle Griffin TW, Wambersie A, Laramore GE, Castro J. H
trials. Int f Radiat Oncol Biol Phys 1988;14:583-92.

13 Zink S, Antoine J, Mahoney FJ. Fast neutron therapy clinical trials in the United States. Am J Clin Oncol 1989;12:277-82.

14 Griffin T, Pajak T, Laramore G, Davis L. Analysis of neutron radiotherap treatment complications. Bull Cancer (Paris) 1986;73:582-6.

15 Bonnett DE, Blake SW, Shaw JE, Bewley DK. The Clatterbridge high-energy neutron therapy facility: specification and performance. $\operatorname{Br} \mathcal{O}$ Radiol 1988;61:38-46.

16 Cox DR. Regression models and life tables (with discussion). Fournal of the Royal Statistical Society $B$ 1972;34:187-220.

17 Elashoff JD. Surviving proportional hazards. Heputology 1983:73:1031-5.

18 Pocock SJ, Hughes MD. Practical problems in interim analyses, with particular regard to estimation. Controlled Clinical Trials 1989;10: particular

19 Armitage P, Berry (i. Statistical methods in medical research. 2nd ed. Oxford: Blackwell Scientific Publications, 1987:460.

20 Fleiss JL. Statistical methods for rates and proportions. New York: John Wiley, 1981:68-75.

(Accepted I March 1991)

\section{Allergy to penicillin: fable or fact?}

\section{S J Surtees, M G Stockton, T W Gietzen}

\section{Abstract}

Objective-To assess whether, on the basis of one blood test, penicillin allergy might be excluded sufficiently for general practitioners to give oral penicillin to patients claiming a history of penicillin allergy.

Design-Prospective study of patients referred by general practitioners.

Setting-Outpatient allergy clinic in a district general hospital.

Patients -175 referred patients who gave a history of immediate type reaction to penicillin, of whom 144 attended as requested and 132 completed the investigations.

Main outcome measures-History and examination, serum radioallergosorbent test to phenoxymethylpenicillin and benzylpenicillin, and oral challenge with penicillin.

Results-Of 132 patients, four were confirmed to have penicillin allergy by the radioallergosorbent test and 128 had an oral penicillin challenge without ill effect.

Conclusions-Most patients who gave a history of penicillin allergy are not so allergic, and their actual allergic state should be substantiated whenever feasible. For patients reporting minor or vague reactions negative findings with a radioallergosorbent test to phenoxymethylpenicillin and benzylpenicillin provide sufficient evidence to give oral penicillin safely.

Department, District

General Hospital,

Eastbourne, East Sussex

BN21 2UD

S J Surtees, FRCPED,

consultant chemical

pathologist

M G Stockton, MB, clinical

assistant

T W Gietzen, MRCGP, clinical assistant

Correspondence to: Dr Surtees.

BMF 1991;302:1051-2 sample that does not demand any special handling or storage.

\section{Patients and methods}

We studied patients referred from local general practitioners. In many cases the referral was a recognition of the need for clarification before labelling the patient as allergic; sometimes "penicillin allergy" had been casually mentioned in the course of history taking. For a few patients treatment with penicillin was indicated and it was necessary to determine whether they were allergic or not. Patients with a classic history of skin rash after receiving ampicillin during an Epstein-Barr type of virus infection were not included.

During 1983-90 there were 175 such referrals to the allergy clinic of this hospital and 144 patients attended as requested; table I shows their sex and age range. In

TABLE I-Age and sex of patients tested for penicillin allergy

\begin{tabular}{lrrrrrrrrr}
\hline & \multicolumn{8}{c}{ Age range (years) } \\
\cline { 2 - 9 } Sex & $0-$ & $15-$ & $25-$ & $35-$ & $45-$ & $55-$ & $65-$ & $\geqslant 75$ & Total \\
\hline Male & 19 & 5 & 5 & 8 & 3 & 2 & 7 & & 49 \\
Female & 17 & 20 & 17 & 18 & 8 & 10 & 4 & 1 & 95
\end{tabular}

132 patients a history was taken, an examination was made, and findings of a radioallergosorbent test to phenoxymethylpenicillin and benzylpenicillin were determined; if the test findings were negative the patient proceeded to a penicillin challenge. This consisted of ingesting a starch capsule followed about 30 minutes later by $250 \mathrm{mg}$ oral phenoxymethylpenicillin as a white tablet. No patient was tested within three months after an alleged reaction to penicillin.

Although anaphylactic reactions are rare after oral administration of penicillin, ${ }^{23}$ full resuscitation facilities were available during the oral challenge and we observed the patients for two hours afterwards and requested them to report any late reaction. 